\title{
The Meaning in the History of Cover of KJCCM
}

\author{
Sung Jin Hong \\ Vice President, The Korean Society of Critical Care Medicine
}

\section{Dear Editor:}

The Korean Journal of Critical Care Medicine (KJCCM) has been using its cover image since 2007 after changing the cover design of its December issue (Vol. 22, No. 2). The previous cover design was simple and concise as it depicted only the logo of KJCCM on a green-colored background. With a growing opinion in favor of updating the cover image, we sought professional help for a new cover design that could better portray the nature of KJCCM. Yoon Ju-Hyeon, Professor at the College of Art and Design, Seoul National University, suggested five different designs. The mainly modern abstract designs provided a glimpse into the contemporary medicine and intensive care units. However, our attention was drawn to one of the illustrations showing a tropical orchid with nothing but a white background (Figure 1).

KJCCM deals with the advanced dynamic academic approaches taken to treat patients with life-threatening illness. But, it was expressed as an orchid drawn on a white background. It seemed puzzling at first. However, we saw the possibility that this exceptional illustration could provide ICU professionals with comfort, albeit momently, given their busy and tense working settings. After the floral design was accepted almost unanimously at the meeting of the Board of Directors, KJCCM adopted it as a new cover image of its journal.

Since then, the floral image has appeared on the cover of white books and treatment guidelines that KJCCM published as if it were a symbol of KJCCM.
Received on February 27, 2018

Accepted on February 27, 2018

\section{Sung Jin Hong}

Department of Anesthesiology, Pain and Critical Medicine, Seoul St. Mary's Hospital, College of Medicine, The Catholic University of Korea, 222 Banpodaero, Seocho-gu, Seoul 06591, Korea

Tel: +82-2-2258-6151

Fax: +82-2-537-1591

E-mail: hongs@catholic.ac.kr

ORCID

Sung Jin Hong

http://orcid.org/0000-0001-9353-2644

*No potential conflict of interest relevant to this article was reported.

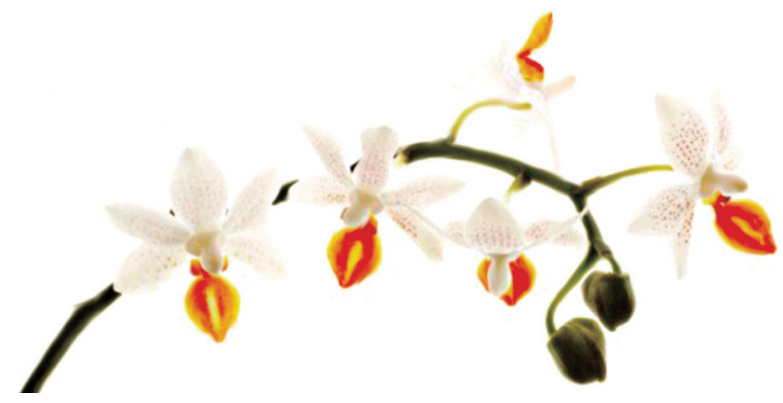

Figure 1. Cover image of KJCCM.

cc This is an Open Access article distributed under the terms of the Creative Commons Attribution Non-Commercial License (http://creativecommons.org/ licenses/by-nc/4.0/) which permits unrestricted non-commercial use, distribution, and reproduction in any medium, provided the original work is properly cited. Copyright (c) 2018 The Korean Society of Critical Care Medicine 